\title{
Successful two-sided sponge pull-through treatment of anastomotic leakage following pancreaticoduodenectomy with pancreaticogastrostomy
}

A 66-year-old man with pancreatic cancer developed an anastomotic leakage of the pancreaticogastrostomy 15 days after pylorus-preserving pancreaticoduodenectomy. An easy-flow drain was identified endoscopically in the extraluminal cavity.

Two-sided sponge (TSS) treatment was initiated [1]. A gastric tube was attached to the outer end of the drain with adhesive tape (Opsite Flexfix; Smith \& Nephew Medical, Hull, UK). The drain was then grasped inside the cavity with a forceps

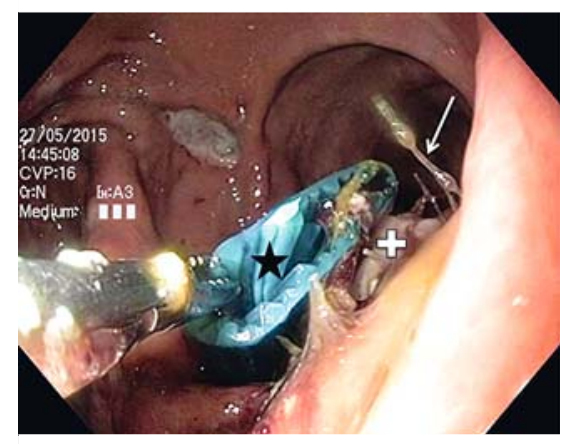

> Fig. 1 Two-sided sponge (TSS) treatment of anastomotic leakage after a pancreaticogastrostomy. A conventional gastric tube has been attached to the outer end of the easy-flow drain. The drain (star) is grasped inside the cavity with an endoscopic forceps and removed through the upper gastrointestinal tract via the mouth. Arrow, anastomotic threads; cross, pancreas.

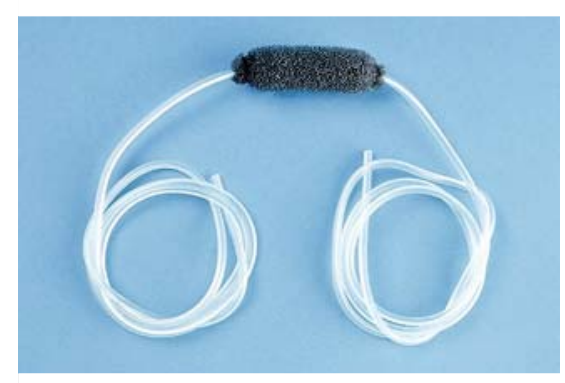

Fig. 2 The prototype two-sided sponge (TSS). The sponge for endoscopic vacuum treatment is mounted centrally on a $160-\mathrm{cm}$ tube. (Source: [1]) (foreign-body removing forceps; MTW Endoskopie Manufaktur, Wesel, Germany) (• Fig. 1, \Video 1). The drain was orally removed, with the gastric tube still attached to its end. The TSS (Braun, Melsungen, Germany) (> Fig. 2) was connected to the gastric tube by adhesive tape, and was drawn into the cavity by pulling the abdominal end of the gastric tube. The oral end of the TSS tube was nasally diverted ( $\triangleright$ Video 1 ). Both ends of the TSS tube were connected to a vacuum pump $(-30 \mathrm{mmHg})$.

When the TSS was changed at day 5 , a clean cavity was seen ( $\triangleright$ Fig. 3 , - Video 1). At day 9, sponge-induced granulation tissue was seen ( $\triangleright$ Video 1 ). A rubber drain was introduced ( $\triangleright$ Fig. 4 ) to promote the formation of granulation tissue and thus definitive healing. At day

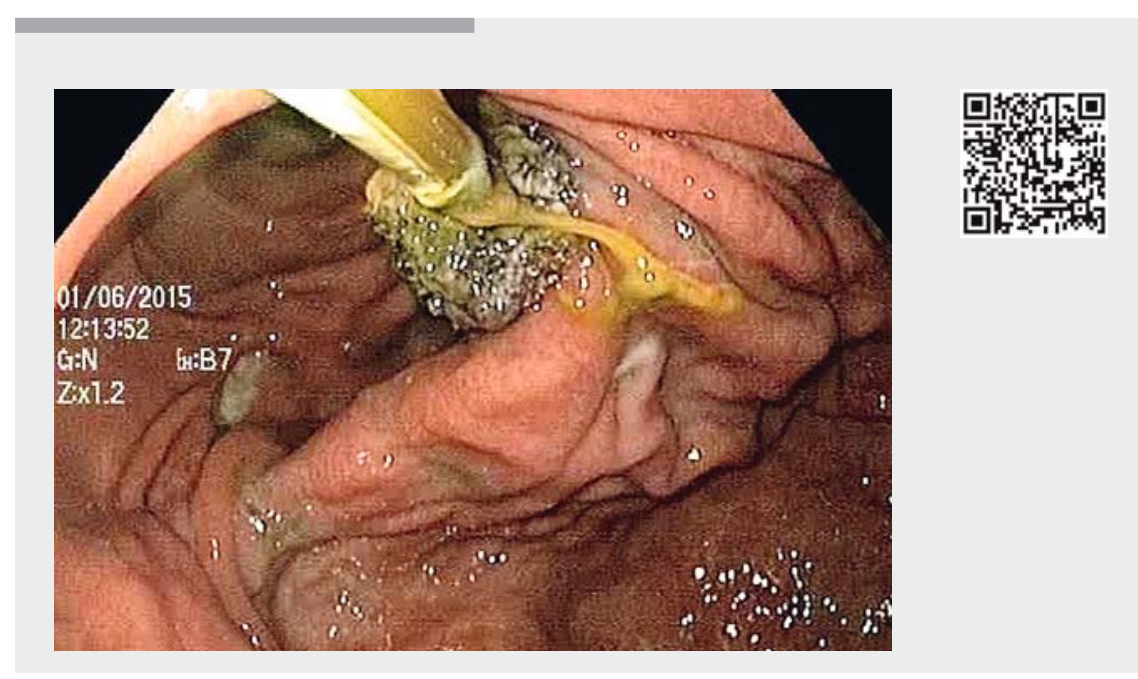

$\checkmark$ Video 1 Endoscopic vacuum treatment, using a two-sided sponge (TSS), of an anastomotic leakage following pancreaticoduodenectomy with pancreaticogastrostomy.
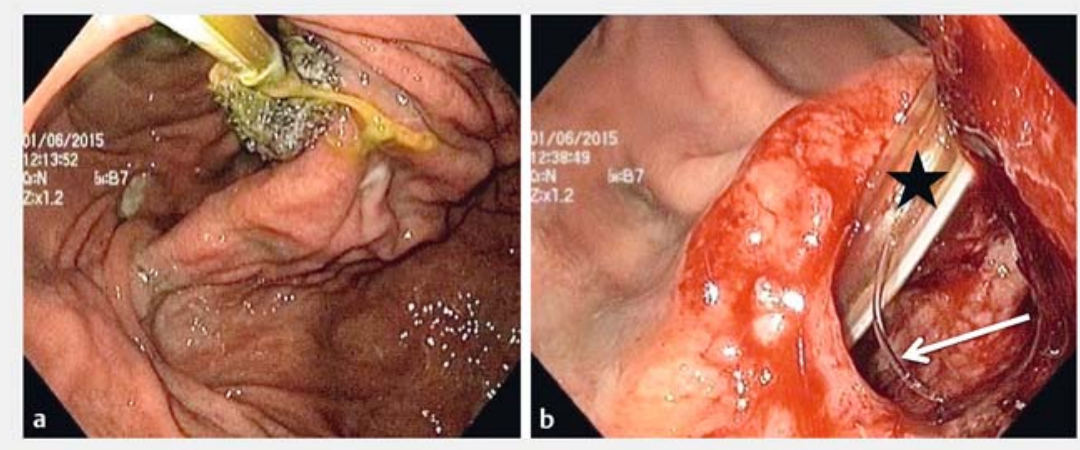

- Fig. 3 First change of the two-sided sponge (TSS) at day 5. a The first TSS in situ before removal. The sponge extends partly into the gastric lumen. $\mathbf{b}$ The well-granulated and clean cavity of the insufficiency after removal of the first TSS. Star, abdominal TSS tube; arrow, thread. 


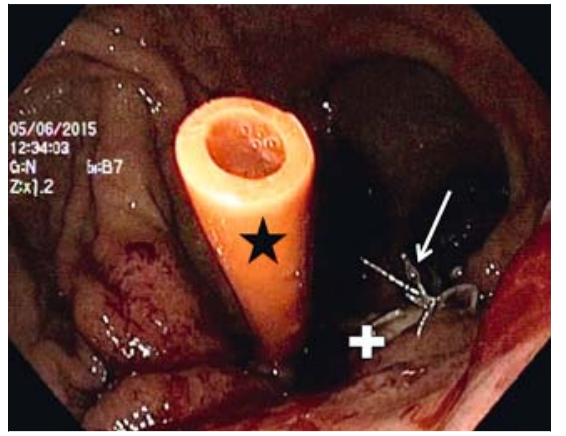

- Fig. 4 Introduction of a rubber tube (star) into the remaining cavity after two two-sided sponge (TSS) changes, at day 9 after initiation of TSS treatment. The tube is being pulled from the stomach into the cavity. The same technique as for TSS placements was used, with the rubber tube being attached to a gastric tube, to lead the rubber tube through the upper gastrointestinal tract and the cavity to the abdominal surface. Arrow, anastomotic threads; cross, pancreas.

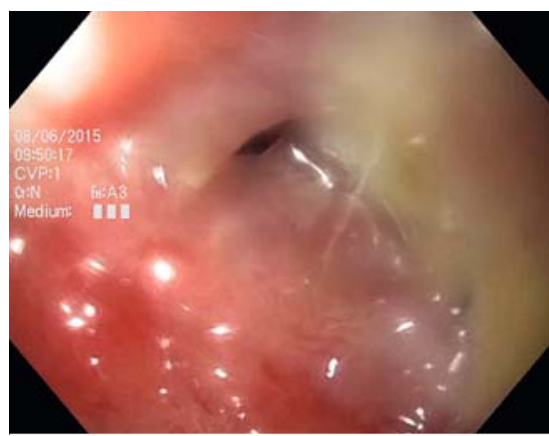

- Fig. 5 After 3 days (day 12), only a fistula opening persisted and the cavity was no longer endoscopically accessible. From that point, the rubber drain was successively drawn back externally.

12 , only a fistula opening persisted ( Fig.5). The rubber drain was successively drawn back over the next days.

Rectal endoscopic vacuum treatment (EVT) with the Endo-SPONGE is well established. Recently a comparable system (Eso-SPONGE; Braun) has been launched for upper gastrointestinal leaks $[2,3]$. The sponge is placed similarly, via an overtube.

Given the diameter of the overtube, leaks have to reach a diameter of $17 \mathrm{~mm}$ (manufacturer's specifications for the smaller Eso-SPONGE version). For smaller anastomotic insufficiencies, sponges may be mounted individually on a gastric tube

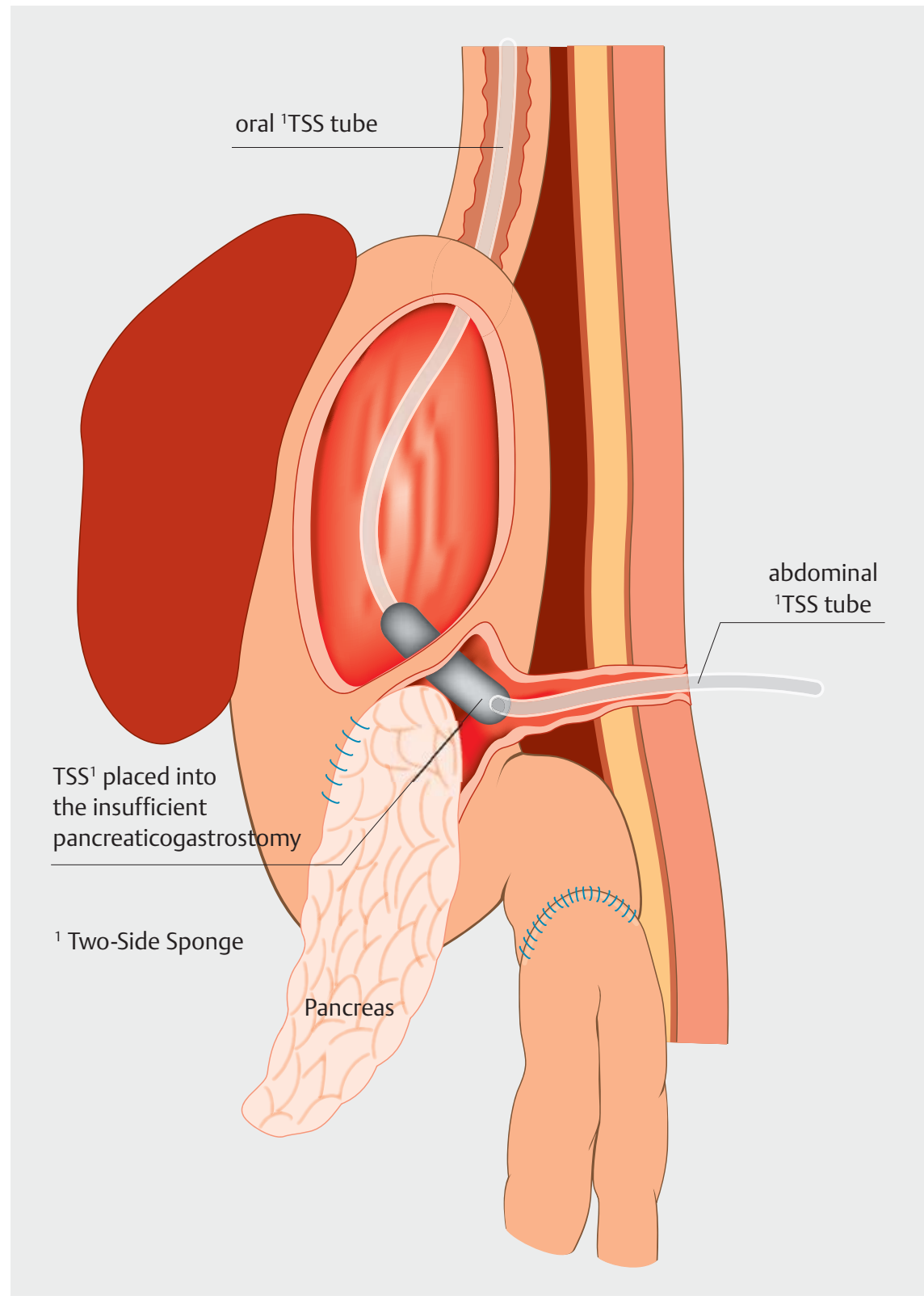

Fig. 6 A posterior-anterior view of a two-sided sponge (TSS) placed in an anastomotic leak following pancreaticogastrostomy. The sponge is introduced into the extraluminal cavity by pulling on the abdominal end of the TTS tube. Precise sponge adjustment is easy because the sponge can be moved bi-directionally by pulling at the oral or the abdominal end of the tube (pendular movement). This procedure is easier and faster compared to the "backpack technique" or the over tube placement of an Eso-SPONGE. However, this technique is only applicable when there is an accessible abdominal drain in the extraluminal cavity. (Source: [1])

$[2,4]$. Introduction into an extraluminal cavity using an endoscopic "backpack technique" is demanding [5], and also it is difficult to access angulated entrances because of the stiffness of the overtube. Use of the TSS ( $\mathbf{F i g . 2}$ ) may simplify these challenges [1]. The sponge is pulled to the target site, which is easier and faster compared to the backpack tech- nique. However, an accessible drain in the extraluminal cavity is required ( Fig. 6).

In anatomically difficult situations the TSS might simplify and extend the therapeutic EVT spectrum.

Endoscopy_UCTN_Code_TTT_1AR_2AK 


\section{Competing interests}

All authors declare no conflicts of interests for this article.

The Authors

\section{Richard F. Knoop, Robert Thimme, Andreas} Fischer

Department of Medicine II, Interdisciplinary Gastrointestinal Endoscopy, Faculty of Medicine, University Hospital Freiburg, Freiburg, Germany

\section{Corresponding author}

\section{Richard F. Knoop, MD}

University Hospital Freiburg,

Interdisciplinary Gastrointestinal Endoscopy, Department of Medicine II, Hugstetter Strasse 55, D-79106 Freiburg, Germany richard.knoop@uniklinik-freiburg.de Fax: +49-761-27033034

\section{References}

[1] Fischer A, Thimme R, Hopt UT et al. Twosided sponge (TSS) treatment: Description of a novel device and technique for endoscopic vacuum treatment (EVT) in the upper gastrointestinal tract. Endosc Int Open 2016; 4: E937-940

[2] Schorsch T, Müller C, Loske G. [Endoscopic vacuum therapy of perforations and anastomotic insufficiency of the esophagus]. Chirurg 2014; 85: 1081 - 1093

[3] Mennigen R, Harting C, Lindner $\mathrm{K}$ et al. Comparison of endoscopic vacuum therapy versus stent for anastomotic leak after esophagectomy. J Gastrointest Surg 2015; 19: $1229-1235$

[4] Loske G, Schorsch T, Müller C. Intraluminal and intracavitary vacuum therapy for esophageal leakage: a new endoscopic minimally invasive approach. Endoscopy 2011; 43: 540 - 544

[5] Mennigen R, Senninger N, Laukoetter MG. Novel treatment options for perforations of the upper gastrointestinal tract: endoscopic vacuum therapy and over-the-scope clips. World J Gastroenterol 2014; 20: 7767 - 7776

\section{Bibliography}

DOI https://doi.org/10.1055/s-0043-113552

Published online: 18.7.2017

Endoscopy 2017; 49: 1010-1012

(c) Georg Thieme Verlag KG

Stuttgart · New York

ISSN 0013-726X

\section{ENDOSCOPY E-VIDEOS}

https://eref.thieme.de/e-videos

口回 Endoscopy E-Videos is a free access online section, reporting 然: on interesting cases and new techniques in gastroenterological endoscopy. All papers include a high quality video and all contributions are freely accessible online.

This section has its own submission website at

https://mc.manuscriptcentral.com/e-videos 